Vol. 1 No. 1, Maret 2021, hlm. 1 -6

DOI: $\operatorname{xxxxxxxxxxxxxxxxx}$

Available online at http://jurnal.stmikroyal.ac.id/index.php/j-com

\title{
SISTEM PENDUKUNG KEPUTUSAN PENENTUAN LOKASI STRATEGIS PERUMAHAN DI WILAYAH KABUPATEN ASAHAN
}

\author{
Annisa Harahap ${ }^{1}$, Rizaldi ${ }^{2 *}$, Andy Sapta ${ }^{2}$ \\ ${ }^{1}$ Mahasiswa Prodi Sistem Informasi, STMIK Royal \\ ${ }^{2}$ Prodi Sistem Informasi, STMIK Royal \\ *email: rizaldipiliang.rp@gmail.com
}

\begin{abstract}
PT. Mitra Zetta Ugraha Lestari is a company engaged in the contractor and developer sector. Company goal to create quality housing with high quality and use value that gives satisfaction to consumers. This study uses the weighted product method. Some of the factors used as measurement tools are density in the population area, land heigh, distance between main roads, distance from shopping centers and market, distance betwen education or school place. The programming language used in this study are visual basic net 2010 and mysql data base
\end{abstract}

Keywords: Decision support system, weighted product method, housing.

Abstrak: PT. Mitra Zetta Ugraha Lestari adalah perusahaan yang bergerak di bidang Kontraktor dan Developer. Tujuan perusahaan Mewujudkan perumahan yang berkualitas dan memiliki nilai jual yang tinggi serta nilai pakai yang memberikan kepuasan pada konsumen. Penelitian ini menggunakan metode weighted product. Beberapa faktor yang menjadi alat ukur adalah kepadatan di area penduduk, ketinggihan tanah, jarak antara jalan utama, jarak dengan sentral perbelanjaan/pasar, jarak antara tempat pendidikan disekolah. Bahasa pemograman yang digunakan pada penelitian ini yaitu Visual Basic NET (VB.NET) 2010 dan MYSQL.

Kata kunci: Sistem pendukung keputusan, metode weighted product, perumahan.

\section{PENDAHULUAN}

Rumah menjadi kebutuhan yang paling utama didalam kehidupan disamping kebutuhan pokok yang lainnya [1]. Pembangunan perumahan yang akan dijalankan oleh developer yang tujuan utamanya adalah terciptanya keamanan dan kenyamanan di dalam lingkungan maupun di luar lingkungan perumahan harus di landaskan pada peraturan-peraturan yang telah di tetapkan. Adapun pemilihan lokasi perumahan yang sangat tepat didukung oleh beberepa faktor utama yaitu, kepadatan diarea penduduk, ketinggian tanah, jarak antara jalan utama, jarak dengan sentral perbelanjaan pasar, jarak antara tempat pendidikan disekolah.

Metode Weighted Product (WP) bersifat kuantitatif dalam pengambilan keputusan. Perhitungan yang menggunakan perkalian untuk menghubungkan rating dari atributnya [2][3]. Sistem penunjang keputusan dapat digunakan sebagai pengambilan keputusan lebih tepat[4][5]. 
Vol. 1 No. 1, Maret 2021, hlm. 1 -6

DOI: $\mathrm{xxxxxxxxxxxxxxxxx}$

Available online at http://jurnal.stmikroyal.ac.id/index.php/j-com

Rumusan masalah pada penelitian adalah bagaimana sistem penunjang keputusan dapat menentukan lokasi strategis dalam pemilihan perumahan, serta penerapan metode dalam membuat keputusan.

Tujuan penelitian ini adalah memudahkan pengembang perumahan untuk menentukan lokasi-lokasi mana saja yang layak untuk dibangun perumahan berdasarkan kriteria-kriteria pendukung seperti yang sudah peneliti jelaskan sebelumnya.

\section{METODE}

Metode yang digunakan yaitu metode kuantitatif, dengan menggunakan angka, mulai dari pengumpulan data, penafsiran terhadap data tersebut, serta penampilan hasilnya. Metode yang digunakan dalam sistem pendukung keputusan adalah penerapan metode weighted product (WP). Metode weighted product (WP) merupakan keputusan analisis multi kriteria yang sangat populer dan metode yang yang efisien dalam mengambil sebuah keputusan.

Dalam menentukan lokasi strategis pemilihan perumahan terdapat 4 kriteria yang digunakan, yaitu : (1) Jarak jalan utama., (2) Jarak pasar., (3) Jarak sekolah., (4) Ketinggian tanah.

Pembobotan pada weighted product dihitung berdasarkan tingkat kepentingan yaituberdasarkan rangking.

Pada tahap penelitian ini ada beberapa tahapan yang dilakukan, yaitu pengumpulan data melalui wawancara dan kuisoner. Faktor utama dalam pemilihan rumah tinggal dengan bobot kepentingan, perhitungan metode weighted product secara manual, perancangan sistem serta pengajuan sistem.

Rumus perhitungan weight product

$$
W j=\frac{\mathrm{W} j}{\Sigma W j}
$$

Nilai akhir alternatif

$$
\mathrm{V} i=\frac{S i}{\sum \mathrm{S} i}
$$

\section{HASIL DAN PEMBAHASAN}

Sistem yang dibangun menghasilkan sistem yang dapat membantu developer dalam menentukan dan memutuskan lokasi mana saja yang akan di bangun perumahan. Output yang di berikan oleh sistem merupakan rekondasi lokasi mulai dari nilai yang tetinggi sampai dengan yang terendah. Berikut tampilan pada sistem: Admin melakukan login, pada tamilan login. 
Vol. 1 No. 1, Maret 2021, hlm. 1 - 6

DOI: $\mathrm{xxxxxxxxxxxxxxxxxx}$

Available online at http://jurnal.stmikroyal.ac.id/index.php/j-com

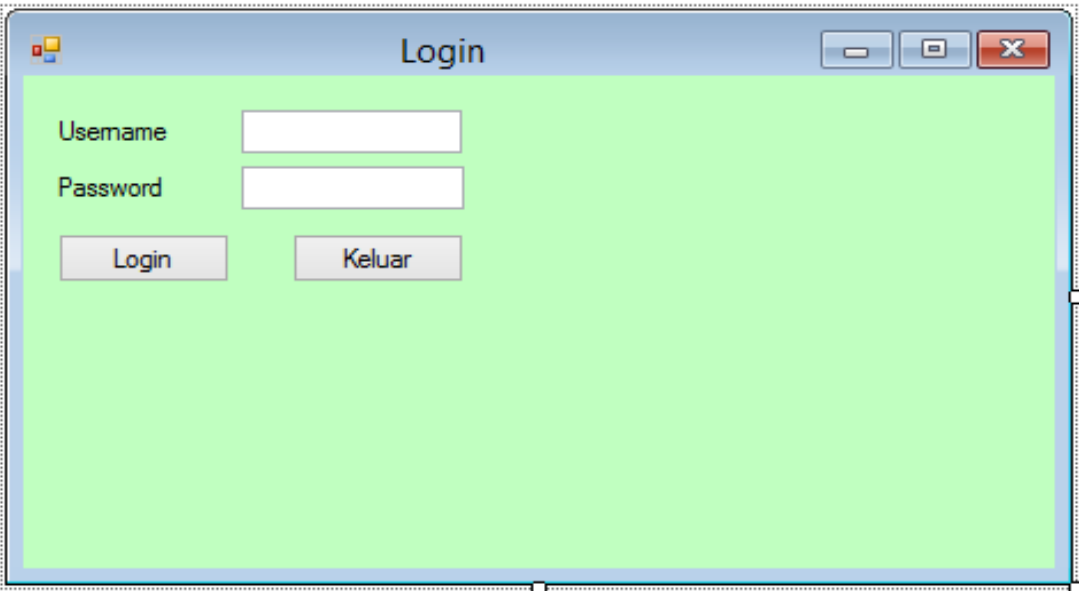

Gambar 1. Tampilan login
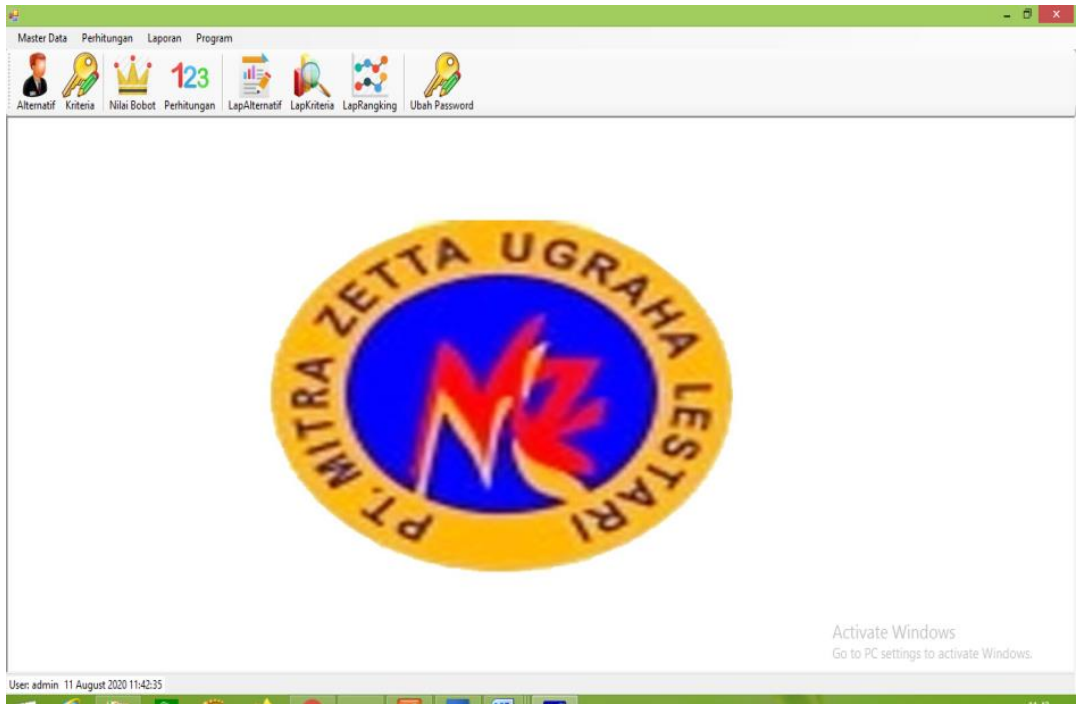

Gambar 2. Tampilan Halaman Utama
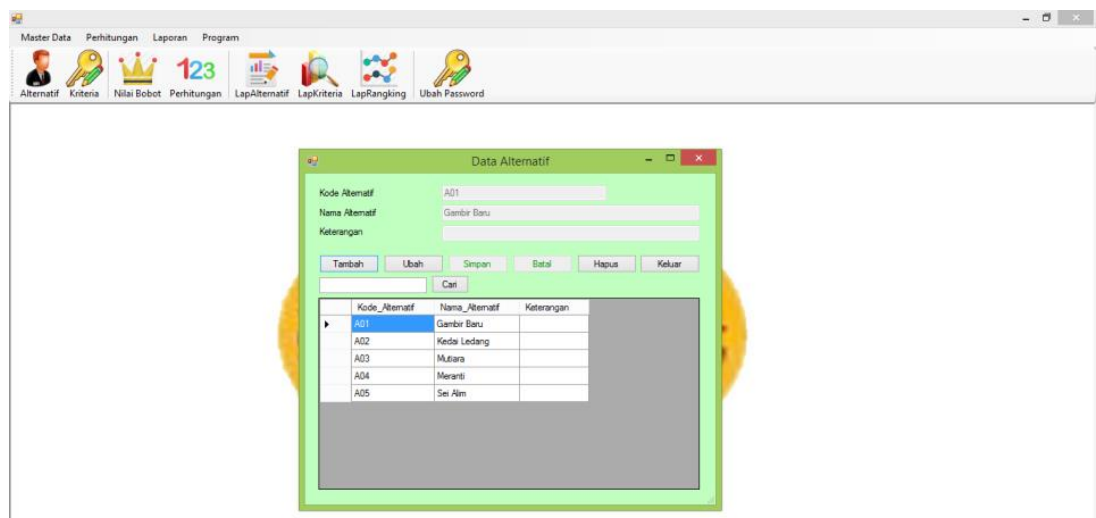

Gambar 3. Tampilan Halaman Implementasi Data Alternatif 
Vol. 1 No. 1, Maret 2021, hlm. 1 - 6

DOI: $\operatorname{xxxxxxxxxxxxxxxxxx}$

Available online at http://jurnal.stmikroyal.ac.id/index.php/j-com

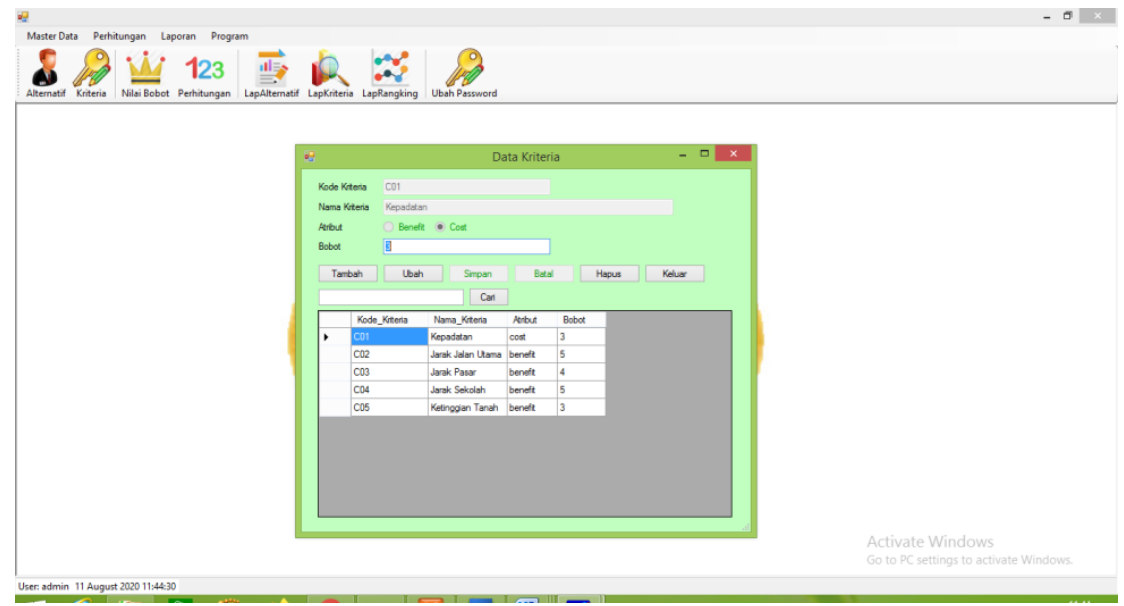

Gambar 4. Halaman Implementasi Kriteria

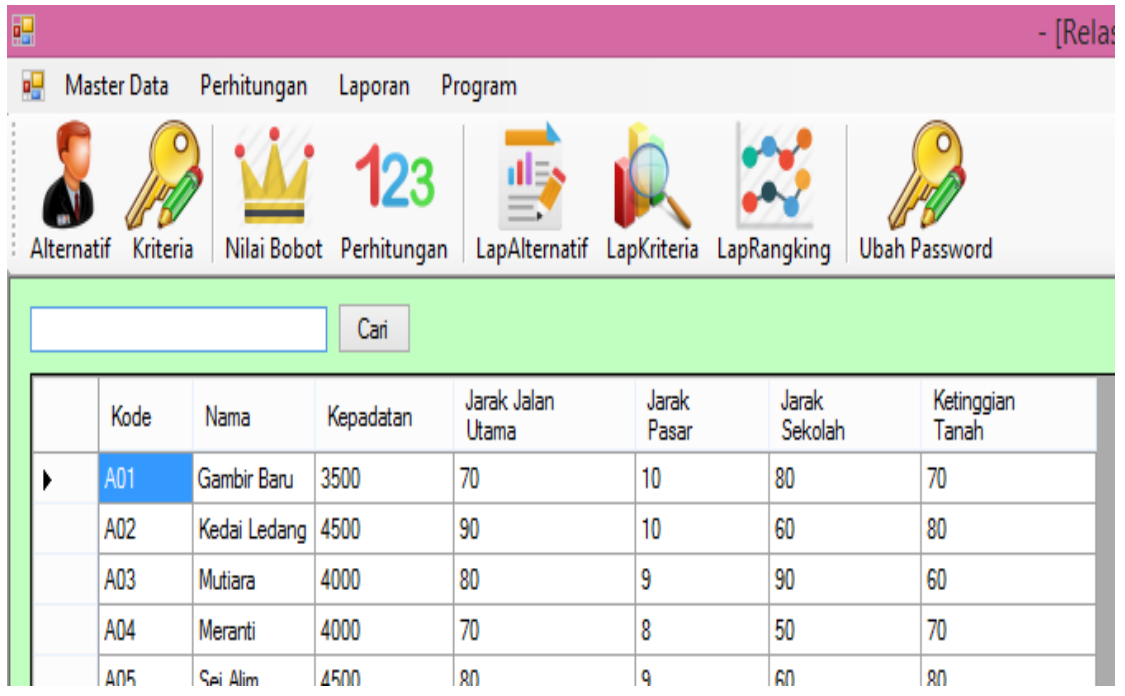

Gambar 5. Halaman Nilai Bobot

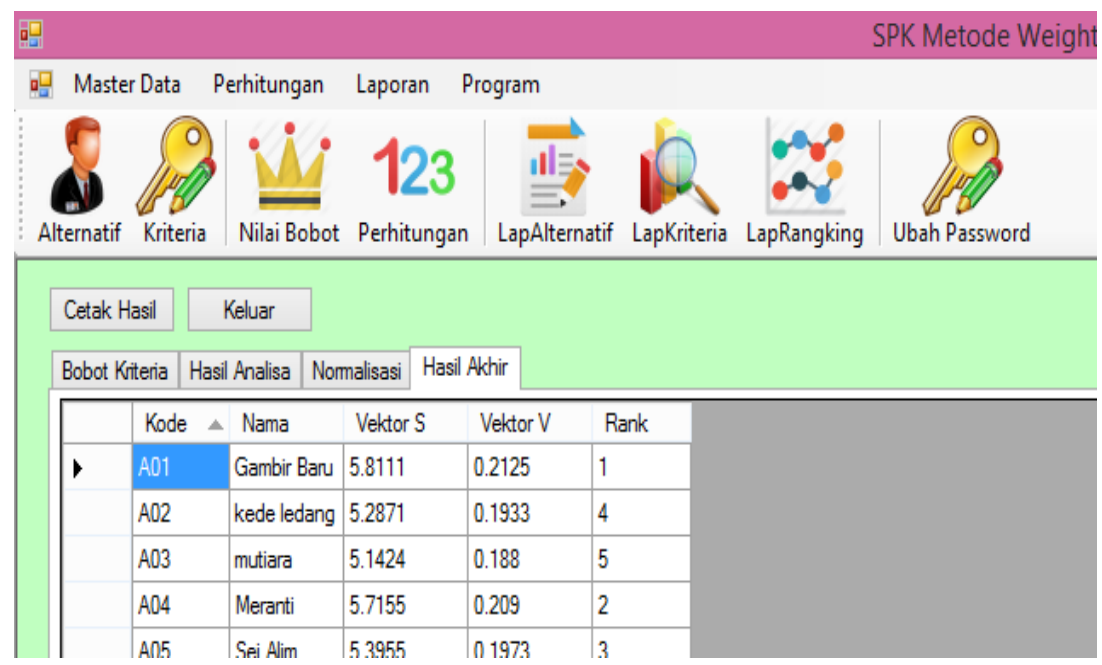

Gambar 6. Tampilan Halaman Pengguna 
Vol. 1 No. 1, Maret 2021, hlm. 1 -6

DOI: $\mathrm{xxxxxxxxxxxxxxxxx}$

Available online at http://jurnal.stmikroyal.ac.id/index.php/j-com

\begin{tabular}{|c|c|c|c|}
\hline Kode & Kritsre & Atribut & Bobot \\
\hline $\cos$ & Kepadatan & $c 0$ & 5 \\
\hline $\cos$ & Jarak Jatan Utama & benet & 4 \\
\hline$c \infty$ & Jarak Fasar & benet & 5 \\
\hline 004 & Jarak Beksiahn & benet & $a$ \\
\hline $\cos$ & Kethaglen Teneh & benet & 2 \\
\hline $\cos$ & Harge & cost & 1 \\
\hline
\end{tabular}

Kiasan

Diketahui Olch,

ZULFAMIRULAF

Gambar 7. Halaman Laporan Alternatif, Kriteria dan Rangking

\section{SIMPULAN}

Berdasarkan dari pembahasan, penulis dapat menarik beberapa kesimpulanyaitu Sistem ini dapat mempermudah develover dalam menentukan lokasi perumahan yang strategis di wilayah Kabupaten Asahan berdasarkan keriteria yang telah ditentukan. Sistem pendukung keputusan penentuan lokasi perumahan strategis di wilayah Kabupaten Asahan dengan menggunakan metode weighted product dapat memastikan semua kriteria ada di setiap lokasi yaitu kepadatan di area penduduk, ketinggihan tanah, jarak antara jalan utama, jarak dengan sentral perbelanjaan/pasar. Dengan adanya sistem pendukung keputusan penentuan lokasi strategis perumahan di wilayah Kabupaten Asahan developer dapat menentukan lokasi secara tersistem.

Adapun saran-saran yang penulis usulkan agar tercapainya tujuan yang di harapkan yaitu sebagai berikut: Untuk memaksimalkan pemakaian dan kelancaran dalam menggunakan aplikasi sistem pendukung keputusan penentuan lokasi perumahan strategis di wilayah Kabupaten Asahan menggunakan metode weighted product, diharapkan admin dapat menguasai teknologi komputer sehingga sistem ini dapat berjalan dengan dengan baik dan efisien. Dimasa yang akan mendatang dengan adanya kemajuan teknologi yang semakin canggih dan maju diharapkan sistem pendukung keputusan penentuan lokasi strategis perumahan di wilayah Kabupaten Asahan dapat melakukan pengembangan.

\section{DAFTAR PUSTAKA}

[1] H. Supriyono and C. P. Sari, "khazanah informatika Pemilihan Rumah Tinggal Menggunakan Metode Weighted Product," pp. 23-28.

[2] J. I. Mulawarman, N. Nurjannah, Z. Arifin, and D. M. Khairina, "SEPEDA MOTOR DENGAN METODE WEIGHTED PRODUCT," vol. 10, no. 2, pp. 26, 2015.

[3] D. Apriliani, S. Wiyono, and S. Mahardhika, "Penerapan Metode Weighted 
Vol. 1 No. 1, Maret 2021, hlm. 1 -6

DOI: $\mathrm{xxxxxxxxxxxxxxxxx}$

Available online at http://jurnal.stmikroyal.ac.id/index.php/j-com

Product Untuk Sistem Pendukung Keputusan Penerima Beasiswa Politeknik Harapan Bersama Tegal," vol. 03, no. 02, pp. 136-142, 2018.

[4] R. R. Yuma. Febby Madona, "DI PERGURUAN TINGGI DENGAN METODE PROFILE MATCHING Implementasi Sistem Implementasi User Interface Implementasi user interface dilakukan," vol. 9986, no. September, pp. 3-6, 2018.

[5] P. M. A. N. Pariaman, "Sistem Pendukung Keputusan Pemilihan Guru Terbaik dengan Metode Weighted Product," vol. 6, no. 2, pp. 310-321, 2019. 